\title{
SINERGIA
}

REVISTA DO INSTITUTO DE CIÊNCIAS ECONÔMICAS, ADMINISTRATIVAS E CONTÁBEIS (ICEAC)

\section{PADRÕES TECNOLÓGICOS NA ATIVIDADE LEITEIRA NA REGIÃO COREDE PRODUÇÃO DO RIO GRANDE DO SUL}

\author{
MARIZA DE ALMEIDA \\ CLAILTON ATAÍDES DE FREITAS* \\ MARCO ANTÔNIO MONTOYA*** \\ RITA INÊS PAETZHOLD PAULI***
}

\section{RESUMO}

O objetivo da pesquisa foi identificar os padrões tecnológicos dentre os tipos de produtores de leite na região Corede Produção, noroeste do Rio Grande do Sul, Brasil, no ano de 2013. Para tanto, utilizou-se estatística multivariada, mais especificamente, análise fatorial exploratória, análise de clusters e análise discriminante múltipla, dados secundários resultantes do Diagnóstico da Produção de Leite no Corede Produção, realizado no ano de 2013, e 24 variáveis relacionadas com características socioeconômicas, administrativas, estruturais, técnicas e de manejo. Com uso dos escores fatoriais e da análise de cluster, identificaram-se três grupos (tipos) de produtores de leite: o grupo A, que apresenta padrão tecnológico avançado; o grupo B, com baixo padrão tecnológico, conhecido como tradicional; e, por fim, o grupo C, que dispõe de padrão tecnológico intermediário. Tais resultados foram verificados com uso da análise discriminante, a qual apontou boa qualidade de acerto, e com variáveis que corroboram para diferenciar os padrões tecnológicos dentre os produtores de leite da região Noroeste Gaúcha, as suas disparidades e seus consequentes níveis de produtividade.

Palavra-Chave: Tecnologia. Produtores de leite. Análise Multivariada.

\section{ABSTRACT}

The objective of the research was to identify the technological patterns among the types of milk producers in Corede Produção region, Northwest of Rio Grande do Sul, Brazil, on 2013. For this purpose, multivariate statistics were used, more specifically, exploratory factor analysis, cluster analysis and multiple discriminant analysis, secondary data resulting from the Diagnosis of Milk Production at Corede Produção carried out on 2013 and, 24 variables related to socioeconomic characteristics, administrative, structural, technical and management. Using factor scores and cluster analysis, three groups (types) of milk producers were identified: group A, which has an advanced technological standard; group B, with low technological standard, known as traditional; and, finally, group C, which have an intermediate technological standard. Such results were verified using discriminant analysis, which indicated good quality of correctness, and with variables that corroborate to differentiate the technological patterns among dairy activity in Northwest region of Rio Grande do Sul, their disparities and their consequent levels of productivity.

Keywords: Technology. Milk producers. Multivariate analysis.

Recebido em: 08-03-2021 Aceito em: 16-07-2021

\section{INTRODUÇÃO}

A maior parte do leite produzido no Brasil deriva da bovinocultura, a qual se faz presente em todas as regiões brasileiras, mas que apresenta diferenças que vêm sendo constatadas pela grande heterogeneidade estrutural e produtiva dos produtores de leite brasileiros. Tais diferenças estão fortemente relacionadas aos fatores climáticos, ambientais e, principalmente, de produção (terra, capital e tecnologias). Esses fatores de

\footnotetext{
" Doutoranda em Economia Aplicada pela Escola Superior de Agricultura Luiz de Queiroz - Universidade de São Paulo (Esalq/USP). Mestre em Economia e Desenvolvimento (PPGE\&D) pela Universidade Federal de Santa Maria. Bacharel em Ciências Econômicas pela Universidade de Passo Fundo (UPF). E-mail: marizaalmeida@usp.br

"*ós-Doutor em Estatística e Experimentação Agropecuária pelo Departamento de Ciências Exatas da Universidade Federal de Lavras (UFLA). Doutor em Ciências (Economia Aplicada) pela Escola Superior de Agricultura Luíz de Queiroz da Universidade de São Paulo (ESALQ/USP). Mestre em Economia Rural pela Universidade Federal do Rio Grande do Sul (UFRGS). Docente da Universidade Federal de Santa Maria (UFSM).

"Noutor em Economia pela Universidade de São Paulo (ESALQ/USP). Mestre em Economia Aplicada pela Universidade Federal do Rio Grande do Sul (UFRGS). Docente na Universidade de Passo Fundo (UPF).

**** Pós-doutora na Cardiff University no País de Gales - Reino Unido em Geography and Planning, no Sustainable Places Research Institute. Doutora em Ciências Econômicas pela Universidade Estadual de Campinas (Unicamp). Mestre em Economia Rural (Campina Grande) pela Universidade Federal da Paraíba (UFPB). Docente na Universidade Federal de Santa Maria (UFSM).
} 
produção sofreram algumas transformações, em sua maioria, na década de noventa quando ocorreu a abertura comercial, aceleramento da globalização, fim do tabelamento dos preços, menor intervenção do Estado, tecnificação da produção e intensificação da competitividade.

Isso pode ser retratado observando alguns números dessa atividade, tal como o aumento na produção de leite no Brasil, que apresentou variação percentual de 131\% (de 19 bilhões para 33,4 bilhões de litros), no período 1990/2017 segundo IBGE (2018b), e a distribuição da produção de leite de vaca dentre os estados brasileiros, destacando os estados de Minas Gerais, Rio Grande do Sul e Paraná, com maior produção. Os produtores dessas regiões, assim como os demais distribuídos pelo Brasil, precisaram se adaptar às transformações, em especial, às tecnológicas ocorridas em toda cadeia leiteira. Segundo Vilela et al. (2016), a tecnologia tornou-se um fator importante no processo produtivo, pois, por meio dela, é possível obter maiores ganhos econômicos (produtividade), menores impactos ambientais e melhor qualidade do produto.

O Rio Grande do Sul foi um dos estados que mais apresentou transformações na pecuária leiteira. A abertura comercial e sua proximidade geográfica com a Argentina e Uruguai fizeram os produtores de leite e as indústrias investirem de maneira expressiva em tecnologia e em pesquisas para aumentarem a sua competitividade e continuar explorando a atividade leiteira. Além disso, é um dos estados brasileiros com maior presença de estabelecimentos agropecuários do tipo agricultura familiar que produzem leite e apresentam cooperativas e de indústrias privadas (Zoccal et al., 2005). Essa conjunção de fatores proporcionaram ao Rio Grande do Sul expressivos ganhos na produção e na produtividade do leite. Destacase que, de 1990 a 2017, a variação percentual da produtividade foi de $169 \%$, passando de 1.237 litros/vaca/ano para 3.326 litros/vaca/ano (IBGE, 2018b).

Face a esse ambiente, estudos sobre o padrão tecnológico, na pecuária leiteira, indicam a existência de pluralismo regional quanto ao uso de insumos, técnicas de manejos e adoção de tecnologias. A tipificação se presta como uma abordagem para se analisar as peculiaridades de uma determinada população, mais especificamente, conhecer a realidade e as características socioeconômicas, produtivas e tecnológicas dos produtores. Para tanto, há várias formas de tipificar os produtores de leite, algumas já consolidadas (especializado e não especializado), outras mais teóricas e as que utilizam critérios estatísticos, principalmente, a análise multivariadas, como a que é utilizada na presente pesquisa. Há, na literatura nacional e internacional, vários estudos que utilizaram análise multivariada (fatorial e de agrupamento) para tipificar os produtores de leite de uma determinada região ou país, tais como: Chinelatto Neto, Castro e Lima (2005), Aleixo, Souza e Ferraudo (2007), Werncke et al. (2016), Castro et al. (2016) e Kaouche-Adjlane, Ghozlane e Mati (2015).

Entretanto, há carência de estudos com propósito de analisar o padrão tecnológico dos diferentes tipos de produtores de leite da região Corede Produção/RS, Brasil, com suporte da tipificação. A presente pesquisa compreende o estudo da região Conselho Regional de Desenvolvimento (Corede) Produção, uma vez que ela se destaca por ser a maior produtora de leite do estado do Rio Grande do Sul, 401 milhões de litros em 2017, e por estar concentrada na Mesorregião Noroeste Rio-grandense, a qual apresentou a maior produção de leite bovino do País em 2017, total de 3.079 .553 mil litros (IBGE, 2018a). Além disso, a região Corede Produção apresentou um crescimento importante da produção leiteira nos últimos anos. Conforme Castro et al. (1998), Zoccal et al. (2005) e Montoya et al. (2014), o desempenho favorável dessa região vincula-se aos aspectos culturais e demográficos, a quase total ausência de limitações climáticas e não menos importante, devido aos menores custos com os componentes terra e mão de obra neste território; e devido à pressão imobiliária na região metropolitana de Porto Alegre na década de 1980, levando as cooperativas e indústrias de processamento a se deslocarem para as regiões Planalto Médio e Alto Uruguai e investirem, de forma expressivam nos produtores de leite de vaca.

Dessa forma, o presente estudo possui como motivação a relevância da cadeia produtiva do leite, pois envolve vários setores da economia; de um lado, estão as agroindústrias processadoras de leite; de outro, as fornecedoras de máquinas, equipamentos e insumos ao produtor, que são importantes na geração de emprego. Como não foram encontrados estudos com propósito de analisar o padrão tecnológico dos diferentes tipos de produtores de leite da região Corede Produção/RS, então, a consecução desta pesquisa poderá ajudar a compreender melhor as peculiaridades produtivas, tecnológicas e socioeconômicas da pecuária leiteira e, assim, servir de apoio no desenho de políticas públicas para o setor nesta região. Assim, o estudo busca contribuir para a literatura existente, apresentando informações sobre os produtores de leite da região Corede Produção/RS e sobre algumas tecnologias que podem influenciar na formação de tipos de produtores de leite.

Em síntese, a proposta é aprofundar a pesquisa sobre a tecnologia em diferentes tipos de produtores de leite na região do Corede Produção, localizado no estado do Rio Grande do Sul. Por ter, nessa região, muitos produtores e contar com a maior produção no País, conforme já sinalizado, o presente estudo objetivou identificar e caracterizar os padrões tecnológicos dentre os tipos de produtores de leite na região Corede Produção/RS no ano de 2013. Para tanto, o estudo encontra-se estruturado em outras quatro seções. A seção 2 aborda a inserção das tecnologias e a identificação dos padrões tecnológicos. Na seção 3 , descreve-se 
metodologia, métodos e dados utilizados para identificação, tipificação e caracterização dos padrões tecnológicos. Na seção 4, apresentam-se os resultados e as discussões. Por fim, na seção 5, têm-se as principais conclusões.

\section{INSERÇÃO DE TECNOLOGIAS DE PRODUÇÃO NA PECUÁRIA LEITEIRA}

A pecuária brasileira leiteira apresentou algumas mudanças a partir da década de noventa, entre elas, destaca-se a competitividade advinda da abertura comercial e do fim do tabelamento de preços que impactou desde os produtores de leite até a indústria processadora. Em função do aumento da competitividade, os ganhos de produtividade na produção de leite foram necessários, os quais podem ser obtidos por meio da combinação ótima dos insumos, juntamente com um adequado aporte tecnológico.

Os insumos utilizados, em um processo produtivo de um determinado bem, são capital, trabalho e terra, que derivam da teoria da produção microeconômica, a qual tem, em sua essência, a função de produção. A função de produção apresenta diferentes combinações dos insumos com dadas tecnologias, quando correta gera ganhos produtivos ao produtor, tornando-o mais competitivo diante do mercado que atua. Tal análise microeconômica pode ser aplicada na produção de leite, por exemplo: para se produzir mais e com qualidade, equipamentos e instalações apropriadas são necessárias; para se usar adequadamente a terra, se requer sementes melhoradas e o preparo do solo precisa ser eficaz; e, para ter mão de obra eficiente, ela precisa ser especializada, exigindo conhecimento e qualificação constante (Aleixo et al. 2007; Castro et al., 1998; Mas-Collel; Whinston; Green, 1995).

A partir dessa análise, da Revolução Verde e das transformações ocorridas da década de noventa em diante (abertura comercial, participação em acordos internacionais de comércio, fim do tabelamento de preços, globalização, aumento da competitividade e implementação do plano real), a produção brasileira leiteira se viu pressionada a realizar mudanças tecnológicas. Vieira e Filho e Silveira (2012) realizam uma análise de como ocorre a mudança tecnológica para explicar o crescimento agrícola, partem de uma análise crítica ao conceito de adoção e difusão tecnológica na agricultura, transitam pelos modelos de dualismo tecnológico, custos de transação, mecanismos de transição e inovação induzida e destacam como abordagem alternativa a mudança tecnológica na agricultura relacionada com a trajetória tecnológica e a acumulação do conhecimento. A trajetória tecnológica e a acumulação do conhecimento, de acordo com Vieira e Filho e Silveira (2012, p. 735), conciliam a diversidade dos agentes e o caráter dinâmico das inovações, ou seja, considera-se a instabilidade estrutural, a competição tecnológica e a racionalidade limitada. Para esses autores, em um ambiente competitivo, como foi o caso da pecuária leiteira, a partir da década de noventa, levaria a uma competição por recursos produtivos e a uma busca por inovação, retratando uma dinâmica evolucionária, mas uma maior concentração do capital regional.

As instituições governamentais como a Empresa Brasileira de Pesquisa Agropecuária (Embrapa), Empresa de Assistência Técnica e Extensão Rural (EMATER), universidades e institutos de pesquisas, ampliaram seus estudos no aprimoramento tecnológico da produção de leite, que foram e ainda estão sendo implementados através de programas e normativas, tais como: Portaria 56; Instrução Normativa no 51 ; Instrução Normativa no 62; Instrução Normativa no 76; Programa Boas Práticas e Bem-estar Animal; Plano de Incentivo à Pecuária Bovina, atualmente, conhecidos como os programas Mais Leite e Mais Carne; e Melhoria de Competitividade (MAPA, 2018; Jank e Galan, 1998; Vilela et al. 2017). Para Vieira e Filho e Silveira (2012), o conhecimento externo, obtido de investimentos em inovação ou imitação, tem como objetivo reduzir os custos e aumentar a produtividade (eficiência). Entretanto, esse objetivo dependerá de como o conhecimento foi assimilado e aplicado pelos produtores na produção. Os autores ressaltam que os produtores têm diferentes habilidades de aprendizagem e gerenciamento, o que influencia no seu processamento e na absorção de informação.

Segundo Montoya et al. (2014) e Zoccal et al. (2005), a assistência técnica, em proximidade com o produtor (redes de técnicos da extensão rural) e com a participação da mão de obra em cursos, dias de campo e palestras, adapta os produtores às tecnologias e às técnicas disponíveis. Através da educação e da assistência técnica, os produtores podem adquirir conhecimento sobre prevenção de doenças, gestão e controle do rebanho, administrar melhor a propriedade e estar informados sobre modernas técnicas que melhoram a produção de leite.

As normativas mostram aos produtores melhores técnicas de manejo e sanidade, pois elas têm grande impacto sobre a qualidade do leite e volume produzido. As técnicas de manejo da plantação e adubação das cultivares aumentam a produção por hectare; a sanidade reduz o número de doenças que produzem a mortalidade, melhora a qualidade do leite e a quantidade produzida, acarretando menores perdas econômicas (Resende et al., 2016; Werncke et al., 2016).

A genética dos animais, a ordenha mecanizada e a alimentação (concentrados, silagem e cultivares) foram aprimoradas. O melhoramento da genética dos animais (tais como utilização racional da seleção e dos sistemas de acasalamento) fornece aumento da produtividade, adaptação para diferentes ambientes e 
sustentabilidade dessa atividade em muitas regiões; a alimentação apresenta valor nutritivo mais alto e melhor cobertura do solo, elevando o potencial produtivo conforme o clima das regiões; a ordenha mecanizada representa as instalações e equipamentos que reduzem o tempo gasto no momento da ordenha e da alimentação (Vilela et al., 2016).

Entretanto, grande parte das tecnologias e técnicas não foram implementadas uniformemente entre os produtores de leite, pois os mesmos possuem diferentes características estruturais, socioeconômicas, edafoclimáticas, logísticas e culturais, que podem limitar a adoção de tecnologias e conduzir a existência de vários padrões tecnológicos. No contexto agropecuário, em específico na pecuária leiteira, alguns estudos apontam grandes disparidades tecnológicas dentre os produtores, existindo uma busca constante em compreender, identificar e tipificar os produtores de leite e suas características.

Uma das formas que se destacou para sintetizar e caracterizar e organizar os processos, fenômenos, fatos, características e indivíduos, de modo que as semelhanças e diferenças sejam mais bem compreendidas, foi a tipologia/tipificação (Kostrowicki, 1977; Wagner, 2003). O uso de tipificação poderá fortalecer a atividade leiteira, pois amplia o conhecimento do contexto econômico, social e tecnológico em que vivem os produtores rurais, muitas vezes, desconhecido pelos gestores públicos, agências de assistência técnica e agroindústrias.

Alguns estudos da literatura nacional e internacional podem ser destacados. Dentre os mais consolidados, têm-se: Jank e Galan (1998) tipificaram os produtores de leite entre especializados e não especializados; Garcia Filho (1999) discriminou os produtores entre produtores familiares, produtores patronais e produtores puramente capitalistas; Wagner et al. (2004) caracterizaram os produtores de leite entre moderno convencional, em transição e tradicional; e, Chinelatto Neto, Castro e Lima (2005) identificaram três grupos, um formado, em sua maioria, por pequenos produtores, e dois, formado por grandes produtores.

Já, dentre os estudos mais atuais, a partir de 2010, destaca-se: Souza (2015) tipificou os produtores em rudimentar, especializado, em transição inicial e em transição avançada; Werncke et al. (2016) identificaram dois tipos de produtores com maior nível tecnológico e um tipo de produtor (menor infraestrutura) com menor nível de tecnologia; Todde et al. (2016) apontaram a existência de três tipos de produtores, os com baixa mecanização, os mecanizados e os com alta mecanização; Castro et al. (2016) constataram a presença de quatro tipos de fazendas após a implantação de um sistema de ordenha: fazendas com mais lazer e qualidade de vida; fazendas que pararam com a produção de leite; fazendas com pouco lazer e agricultores sem sucessor; e as que a mecanização cobriu as expectativas dos agricultores; Lange et al. (2016) identificaram a formação de cinco grupos distintos de sistemas de produção, sendo que as principais características que diferenciam os grupos foram com relação às características dos sistemas de produção; Guamán, Moposita e Rodríguez (2017) constataram três Sistemas de Produção (SP): o SP1, com níveis mais baixos de tecnologia; o SP2, com níveis tecnológicos intermediários e o SP3, com maior desenvolvimento tecnológico. Cervo et al. (2018) realizam discriminação da bovinocultura leiteira nos municípios dos estados de Santa Catarina e Rio Grande do Sul, identificam cinco clusters de municípios: baixa produção; média e alta produção; alta produção; média produção; média e baixa produção; e Perobelli, Araújo e Castro (2018) buscaram traçar os diferentes tipos de municípios mineiros produtores de leite; oito tipologias de municípios foram identificadas, sendo eles: grande oferta de leite; oferta de leite e baixa renda; propriedades rurais e laticínios de grande porte; propriedades rurais e laticínios de médio porte; propriedades rurais e laticínios de pequeno porte; centros urbanos; municípios com baixa participação na cadeia produtiva e municípios com baixo nível de renda. Portanto, as pesquisas realizadas, na área de tipificação dos produtores de leite, principalmente pelo seu padrão tecnológico, sugerem que há disparidades tecnológicas e, consequentemente, diferentes níveis de produtividade.

\section{METODOLOGIA}

\subsection{Caracterização da amostra}

Este estudo foi realizado utilizando a base de dados obtida da pesquisa "Diagnóstico da Produção de Leite - Corede Produção", conduzida pela Universidade de Passo Fundo (UPF), de março a novembro de 2013, com dados referentes ao ano de 2012, na região Corede Produção, formada por 21 municípios do Rio Grande do Sul, Brasil, apresentados na Figura 1. O levantamento desses dados foi realizado por meio de uma amostragem semiestratificada, probabilística e com população finita, compreendendo uma amostra de 194 produtores de leite (Montoya et al., 2014). 
Figura 1 - Localização do Corede Produção

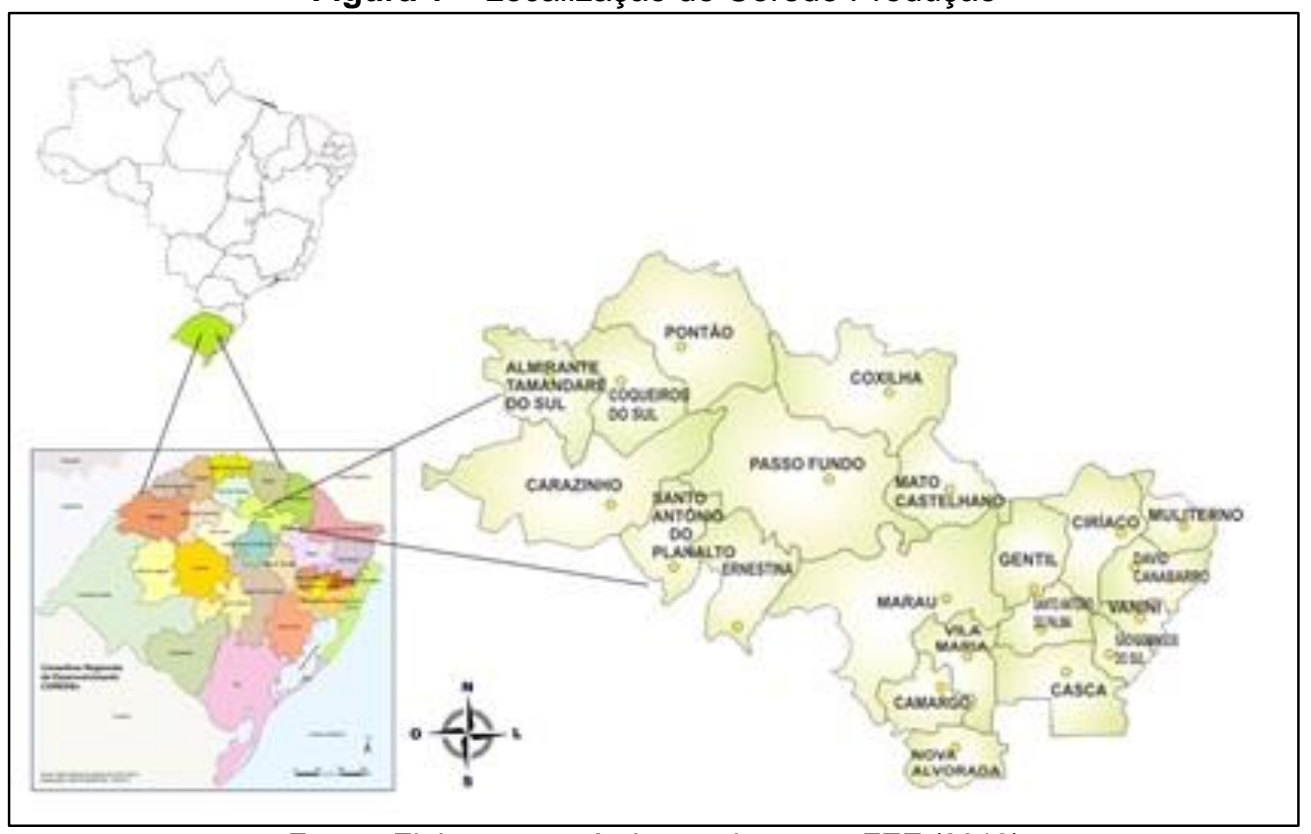

Fonte: Elaboração própria com base em FEE (2018)

Os dados retratam aspectos produtivos das propriedades e características dos produtores, permitindo um estudo detalhado dos padrões tecnológicos dos produtores de leite amostrados. As informações incluem o perfil dos produtores de leite, o processo de sucessão, importância econômica da atividade leiteira, uso da terra, rebanho, qualidade do leite, gerenciamento, capacitação da mão de obra, técnicas de manejo e sanidade. As variáveis utilizadas totalizam 24, conforme descritas na Tabela 1. A escolha das variáveis usadas, no presente estudo, está fundamentada na literatura nacional e internacional sobre tipificação de produtores de leite, tais como: Aleixo et al. (2007); Chinelatto Neto, Castro e Lima (2005); Guamán, Moposita e Rodríguez (2017); Souza (2015); Todde et al. (2016); Lange et al. (2016); Wagner et al. (2004); e, Werncke et al. (2016).

Tabela 1 - Estatística descritiva das variáveis ${ }^{1}$ utilizadas

\begin{tabular}{l|l|l|c|c}
\hline Sigla & Variável & Descrição & Média & Desvio-padrão \\
\hline$X_{1}$ & Produção de leite & litros/dia & 300,31 & 514,09 \\
\hline$X_{2}$ & $\begin{array}{l}\text { Distância da propriedade da } \\
\text { sede do município }\end{array}$ & Km & 6,62 & 3,83 \\
\hline$X_{3}$ & Tipo de sistema de produção & $\begin{array}{l}\text { (1) Semiconfinado } \\
\text { (0) A pasto }\end{array}$ & 0,25 & 0,43 \\
\hline$X_{4}$ & Área total gado de leite & Hectares & 14,02 & 14,28 \\
\hline$X_{5}$ & Vacas em lactação & Quantidade (cabeça) & 18,92 & 24,51 \\
\hline$X_{6}$ & $\begin{array}{l}\text { Renda bruta anual que } \\
\text { provém do leite }\end{array}$ & R $\$$ /ano & $86.820,17$ & $163.737,34$ \\
\hline$X_{7}$ & Idade do produtor & Anos & 48,85 & 12,85 \\
\hline$X_{8}$ & Escolaridade do produtor & Anos de escola & 6,78 & 3,32 \\
\hline$X_{9}$ & $\begin{array}{l}\text { Tempo que é produtor de } \\
\text { leite }\end{array}$ & Anos & 19,51 & 13,61 \\
\hline$X_{10}$ & $\begin{array}{l}\text { Número de filhos trabalhando } \\
\text { na produção de leite }\end{array}$ & Quantidade & 0,52 & 0,70
\end{tabular}

\footnotetext{
${ }^{1}$ Dentre as variáveis utilizadas, a maioria é dummy, ou seja, apresenta valor 1 (Sim) ou 0 (Não). As variáveis $X_{1}, X_{6}, X_{17}$ e $X_{23}$ foram construídas da seguinte maneira: $X_{1}$ é a média aritmética da produção de leite na seca e nas águas (L/dia); $X_{6}$ resulta da multiplicação do número de litros de leite vendido pelo preço unitário do litro de leite $(\mathrm{R} \$) ; X_{17}$ é construída por meio da média aritmética das variáveis cuidados sanitários (tipos de vacinas): aftosa, brucelose, manqueira ou mal de ano, paratifo, raiva e vermífugo (em relação à vaca); e $X_{23}$, que é a média aritmética entre a produtividade na seca (litros/vaca/dia) e a produtividade nas águas (litros/vaca/dia).
} 


\begin{tabular}{|c|c|c|c|c|}
\hline Sigla & Variável & Descrição & Média & Desvio-padrão \\
\hline$X_{11}$ & $\begin{array}{l}\text { Esposa executando algum } \\
\text { trabalho na produção de leite }\end{array}$ & $\begin{array}{l}\text { (1) } \operatorname{Sim} \\
\text { (0) Não }\end{array}$ & 0,84 & 0,37 \\
\hline$X_{12}$ & Mão de obra contratada & $\begin{array}{l}\text { (1) } \operatorname{Sim} \\
\text { (0) Não }\end{array}$ & 0,09 & 0,29 \\
\hline$X_{13}$ & $\begin{array}{l}\text { Participação em algum } \\
\text { treinamento (curso, palestra, } \\
\text { dia de campo) }\end{array}$ & $\begin{array}{l}\text { (1) Sim } \\
\text { (0) Não }\end{array}$ & 0,46 & 0,50 \\
\hline$X_{14}$ & $\begin{array}{l}\text { Técnico visitou sua } \\
\text { propriedade para orientá-lo } \\
\text { sobre gado de leite }\end{array}$ & $\begin{array}{l}\text { (1) De } 1 \text { a } 2 \text { visitas no ano, } \\
\text { de } 3 \text { a } 6 \text { visitas no ano, mais } \\
\text { de } 6 \text { visitas no ano } \\
\text { (0) Não foi visitado no último } \\
\text { ano }\end{array}$ & 0,76 & 0,43 \\
\hline$X_{15}$ & $\begin{array}{l}\text { Fez uso do crédito rural no } \\
\text { último ano }\end{array}$ & $\begin{array}{l}\text { (1) Sim } \\
\text { (0) Não }\end{array}$ & 0,61 & 0,49 \\
\hline$X_{16}$ & Uso de concentrado & $\begin{array}{l}\text { (1) Sim } \\
\text { (0) Não }\end{array}$ & 0,82 & 0,38 \\
\hline$X_{17}$ & Sanidade & Média aritmética & 0,56 & 0,19 \\
\hline$X_{18}$ & Ordenhas realizadas por dia & $\begin{array}{l}\text { (1) uma } \\
\text { (2) duas } \\
\text { (3) três }\end{array}$ & 2,01 & 0,07 \\
\hline$X_{19}$ & Tipo de aleitamento & $\begin{array}{l}\text { (1) artificial } \\
\text { (0) natural }\end{array}$ & 0,68 & 0,47 \\
\hline$X_{20}$ & Resfriamento de leite & $\begin{array}{l}\text { (1) Tanque de expansão } \\
\text { individual } \\
\text { (0) Outra maneira }\end{array}$ & 0,84 & 0,37 \\
\hline$X_{21}$ & Leite avaliado por qualidade & $\begin{array}{l}\text { (1) Sim } \\
\text { (0) Não }\end{array}$ & 0,86 & 0,35 \\
\hline$X_{22}$ & O que precisa melhorar & $\begin{array}{l}\text { (1) Orientação técnica } \\
\text { (2) Treinamento de } \\
\text { capacitação dos empregados } \\
\text { (3) Tanque de resfriamento } \\
\text { (4) Melhoria das estradas até } \\
\text { a propriedade } \\
\text { (5) Acesso ao crédito rural }\end{array}$ & 1,76 & 1,41 \\
\hline$X_{23}$ & Produtividade média & litros/vaca/dia & 15,13 & 7,30 \\
\hline$X_{24}$ & Raça & $\begin{array}{l}\text { (1) Puro holandês } \\
\text { (0) Diversas raças }\end{array}$ & 0,39 & 0,49 \\
\hline
\end{tabular}

Fonte: Elaboração própria com base no questionário "Diagnóstico da Produção de Leite - Corede Produção"

A partir da Tabela 1, destaca-se que as propriedades são caracterizadas por pequenas áreas destinadas à produção de leite (média 14 hectares), mão de obra basicamente familiar. O perfil médio do produtor e de sua família é de idade relativamente alta, baixa escolaridade, renda bruta mensal considerada mediana e participação ativa dos filhos e esposa na produção de leite. Com relação à capacitação e aos fatores de produção, a maioria dos estabelecimentos receberam assistência técnica, apresentam ordenha mecânica, resfriamento de leite em tanque de expansão individual e usam concentrados na alimentação do rebanho. De modo geral, observa-se que os produtores apresentam cuidados com o manejo, sanidade e alimentação dos animais, gerando produtos de qualidade para a região.

\subsection{Breve apresentação dos métodos}

Os métodos utilizados para o tratamento dessas variáveis buscam identificar e caracterizar o padrão tecnológico entre os tipos de produtores de leite e analisar a influência dos fatores tecnológicos da diferenciação dos tipos, por meio de análise fatorial exploratória, análise de agrupamento (cluster) e análise discriminante múltipla.

Com o intuito de reduzir a dimensão dos dados, usa-se a análise fatorial, a qual busca agrupar as variáveis que são fortemente correlacionadas entre si, construindo fatores, que, por sua vez, são ortogonais (são independentes entre si) e apresentam uma estrutura dos dados simplificada e com melhor entendimento (Hair et al., 2009; Mingoti, 2005). O modelo de análise fatorial é construído com base na matriz de correlação 
que estabelece relação entre os fatores comuns (desconhecidos) $\left(F_{j}\right)$ e as variáveis originais $\left(X_{i}\right)$. A especificação do modelo de análise fatorial, segundo Mingoti (2005), é representada pela Equação (1):

$$
X_{p}=l_{p 1} F_{1}+l_{p 2} F_{2}+\cdots+l_{p m} F_{m}+\varepsilon_{p}
$$

em que $\varepsilon_{p}$ é o erro de medida, e a variação de $X_{i}$, que não são expressas pelos fatores, $F_{j}$. E, $l_{i j}$ é o coeficiente (cargas fatoriais) que representa o grau de relacionamento entre $X_{i}$ e $F_{j}$, sendo que, $i=1,2, \ldots, p$ são as observações e $j=1,2, \ldots$, m são os fatores.

Após obter a matriz de correlação das variáveis, encontrou-se os $m$ fatores, os quais são definidos usando o critério que considera os autovalores maiores ou iguais a unidade (Corrar et al., 2009). Encontrado o número de fatores, estimaram-se as cargas fatoriais obtidas pelo método de Componentes Principais e realizou-se a rotação ortogonal, utilizando o critério Varimax (Corrar et al., 2009; Hair et al., 2009). Para identificar se os dados estão adequados para a análise fatorial, alguns testes foram realizados, tais como: Kaiser-Meyer-Olkin (KMO), que indica o quanto adequado um modelo de análise fatorial está, ele varia de 0 a 1; e Esfericidade de Bartlett, que verifica se a matriz de correlação populacional é próxima ou não da matriz identidade (Corrar et al., 2009; Hair et al., 2009; Mingoti, 2005).

Por meio da análise fatorial, calcularam-se os escores fatoriais, os quais foram utilizados para agrupar as observações (produtores de leite). A análise de agrupamento tem por objetivo principal dividir os elementos da amostra em grupos conforme suas características. Assim, os produtores com características similares tendem a pertencer ao mesmo conjunto (homogêneos) e ao mesmo tempo os produtores com características diferentes pertencem a conjuntos diferentes (heterogêneos).

Para construção dos clusters, usou-se como técnica de aglomeração o método hierárquico aglomerativo de Ward. Esse método apresentou como critério de agrupamento a medida de distância Euclidiana e forneceu a melhor classificação das propriedades produtoras de leite (Corrar et al., 2009; Hair et al., 2009).

Em um terceiro momento, após o agrupamento dos produtores, foi realizada a análise discriminante para testar a classificação dos produtores, fornecida pela análise de clusters, e identificar quais variáveis tecnológicas apresentam maior poder discriminatório dos grupos. A análise discriminante múltipla é uma técnica utilizada para classificar ou discriminar elementos em um determinado grupo (Mingoti, 2005).

A verificação da classificação dos produtores de leite, em diferentes grupos, foi obtida por uma função matemática que considera um conjunto de variáveis. Essa função é definida por um critério discriminatório, entre eles, destacam-se: função linear de Fischer e a função quadrática. A definição do critério a ser utilizado foi feita pelo Teste M-Box, em que a hipótese nula $\left(\mathrm{H}_{0}\right)$ é que as variâncias dos grupos são iguais. Se rejeitar a hipótese nula, realiza-se a função discriminante quadrática, caso contrário, a função linear de fischer é a mais indicada (Hair et al. 2009; Reis, 1997).

Dada a verificação da classificação, sabendo que as variáveis podem ser usadas para classificar outros produtores de leite, foi estimado um conjunto de funções discriminantes para identificar a contribuição de cada variável na diferenciação dos grupos. Para a estimação da função, foi necessário definir o número de funções pelos $g$ grupos, isto é, $g-1$ (Corrar et al., 2009; Mingoti, 2005). Alguns testes, na análise discriminante, foram necessários para verificar a qualidade de ajuste das funções, apresentados no Quadro 1.

\begin{tabular}{|l|l|}
\multicolumn{2}{|c|}{ Quadro 1 - Testes necessários para analisar as funções discriminantes } \\
\hline $\begin{array}{l}\text { Teste da razão de verossimilhança } \\
\text { com correção de primeira ordem de } \\
\text { Batlett }\end{array}$ & $\begin{array}{l}H_{0} \text { : a matriz de variância-covariância é } \\
\text { diagonal. } \\
\text { Utiliza a estatística qui-quadrado }\left(X^{2}\right) .\end{array}$ \\
\hline Teste da matriz de var-cov esférica & $\begin{array}{l}H_{0} \text { : var-cov é esférica; } \\
\text { Utiliza a estatística qui-quadrado }\left(X^{2}\right) .\end{array}$ \\
\hline Teste composto & $\begin{array}{l}H_{0} \text { : matriz de covariância é simétrica composta } \\
\text { Utiliza a estatística qui-quadrado }\left(X^{2}\right) .\end{array}$ \\
\hline Teste M-Box & $\begin{array}{l}H_{0} \text { : variâncias dos grupos são iguais. } \\
\text { Utiliza a estatística qui-quadrado }\left(X^{2}\right) .\end{array}$ \\
\hline Teste Lambda Wilks & $\begin{array}{l}H_{0}: \text { função estimada não discrimina os grupos. } \\
\text { Utiliza a estatística } F .\end{array}$ \\
\hline
\end{tabular}

Fonte: Elaboração própria, com base em Corrar et al. (2009), Reis (1997) e Mingoti (2005)

As variáveis selecionadas para a análise discriminante estão relacionadas com fatores tecnológicos: área total destinada ao gado de leite, ordenhas realizadas por dia, resfriamento de leite, mão de obra contratada, esposa executa algum trabalho na produção de leite, número de filhos trabalhando na produção de leite, raça, uso de concentrados e produtividade. 


\section{RESULTADOS E DISCUSSÕES}

Com o advento do progresso tecnológico, os produtores de leite precisaram se adaptar ao novo contexto do setor leiteiro implementando mudanças na base técnica da produção para não serem excluídos do mercado. Diante dessas mudanças, o pluralismo, na atividade leiteira, se fez presente entre os produtores amostrados, tornando-se importante identificar o padrão tecnológico dentre os tipos de produtores de leite da região Corede Produção/RS.

Os estabelecimentos produtores de leite da região Corede Produção/RS caracterizam-se por pequenas áreas destinadas à produção de leite e à mão de obra basicamente familiar. Grande parte dos entrevistados recebem assistência técnica, apresentam ordenha mecânica, têm resfriamento de leite em tanque de expansão individual e usam concentrados na alimentação do rebanho. Além disso, destaca-se que, com o uso predominante do sistema de produção a pasto, os estabelecimentos apresentam, em média, uma produção de leite de 300 litros/dia, produtividade de 15 litros/vaca/dia e 19 vacas.

A análise fatorial, utilizada com o intuito de reduzir o número de variáveis que expressam as características socioeconômicas, administrativas, estruturais, técnicas e de manejo das propriedades produtoras de leite, apresentou-se adequada. Isso se deve aos dois testes que verificaram a adequabilidade dos dados para a análise: teste Kaiser-Meyer-Olkin (KMO) ${ }^{2}$, que apresentou uma grandeza de 0,7280, e a esfericidade de Bartlett foi significativa estatisticamente a $1 \%$, indicando que a análise fatorial pode ser realizada.

Utilizando-se o método de análise fatorial em componentes principais, obtiveram-se oito fatores. Esses fatores expressam $67,4 \%$ da variância explicada acumulada (Tabela 2 ) e foram escolhidos por meio do critério que considera os autovalores maiores ou iguais à unidade.

Tabela 2 - Fatores, raízes características e variâncias explicadas

\begin{tabular}{cccc}
\hline Fatores & Autovalor & \% da variância & \% acumulado \\
\hline 1 & 4,607 & $20,94 \%$ & $20,94 \%$ \\
\hline 2 & 2,503 & $11,38 \%$ & $32,32 \%$ \\
\hline 3 & 1,700 & $7,73 \%$ & $40,05 \%$ \\
\hline 4 & 1,503 & $6,83 \%$ & $46,88 \%$ \\
\hline 5 & 1,220 & $5,55 \%$ & $52,43 \%$ \\
\hline 6 & 1,183 & $5,38 \%$ & $57,81 \%$ \\
\hline 7 & 1,099 & $5 \%$ & $62,81 \%$ \\
\hline 8 & 1,031 & $4,69 \%$ & $67,50 \%$ \\
\hline
\end{tabular}

Fonte: Elaboração própria com base nos resultados da pesquisa

$\mathrm{Na}$ Tabela 3, estão apresentados os coeficientes de correlação (cargas fatoriais) entre as variáveis observadas e os fatores. Para se obter esses coeficientes, realizou-se a rotação ortogonal pelo método Varimax. As cargas fatoriais variam de 0 a 1 , em que 0 indica pouca associação e 1 alta associação, escolheuse analisar as cargas fatoriais iguais ou superiores a 0,5, pois, de acordo com Reis (1997), os coeficientes com esses valores são considerados significativos.

Tabela 3 - Cargas fatoriais após a rotação ortogonal e as comunalidades

\begin{tabular}{|c|c|c|c|c|c|c|c|c|c|}
\hline Variável & $\begin{array}{c}\text { Fator } \\
1\end{array}$ & Fator & $\begin{array}{c}\text { Fator } \\
3\end{array}$ & $\begin{array}{c}\text { Fator } \\
4\end{array}$ & $\begin{array}{c}\text { Fator } \\
5\end{array}$ & $\begin{array}{c}\text { Fator } \\
6\end{array}$ & $\begin{array}{l}\text { Fator } \\
7\end{array}$ & $\begin{array}{c}\text { Fator } \\
8\end{array}$ & Comunalidade \\
\hline Produção de leite & 0,9780 & $0, \overline{-}$ & 0,0158 & 0,0 & 0,0088 & 0,0691 & 0,0366 & 0,0152 & 0,0340 \\
\hline $\begin{array}{l}\text { Área total gado de } \\
\text { leite }\end{array}$ & 0,7040 & 0,0717 & 0,2063 & 0,1179 & $\begin{array}{c}- \\
0,1401\end{array}$ & 1503 & 0,1746 & 0,0657 & 0,3677 \\
\hline Vacas em lactação & 0,9475 & $\begin{array}{c}- \\
0,0255\end{array}$ & $\overline{-} \overline{0}-\overline{17}$ & 0,1041 & $\overline{-}$ & 0,0362 & 0,008 & 0,0369 & 0,0854 \\
\hline $\begin{array}{l}\text { Renda bruta anual } \\
\text { que provém do leite }\end{array}$ & 0,9628 & $-0,01$ & 0,0036 & 0,0304 & $\begin{array}{c}- \\
0,0266\end{array}$ & 0,0516 & 0,0272 & 0,0334 & 0,0663 \\
\hline $\begin{array}{l}\text { Mão de obra } \\
\text { contratada }\end{array}$ & 0,6621 & $-0,063$ & 0,0546 & 0,0026 & $\begin{array}{c}- \\
0,3241\end{array}$ & $0, \overline{17}$ & 0,0539 & $\begin{array}{c}- \\
0,0517\end{array}$ & 0,4095 \\
\hline $\begin{array}{l}\text { Número de ordenhas } \\
\text { realizadas por dia }\end{array}$ & 0,6241 & 0,0137 & $0, \overline{0}$ & $0, \overline{1783}$ & 0,4185 & 0,0887 & 0,0618 & 0,0377 & 0,3918 \\
\hline Idade do produtor & 0,0199 & 0,8968 & 0,0018 & 0,1726 & 0,0864 & 0,0128 & 0,0702 & $0, \overline{0}$ & 0,161 \\
\hline
\end{tabular}

\footnotetext{
${ }^{2}$ Para Mingoti (2005), valores de KMO, abaixo de 0,6, são regulares, ruins ou inadequados e valores acima de 0,7 são bons, ótimos e excelentes. Quanto mais próximo de 1, mais adequados estão os dados para análise fatorial.
} 


\begin{tabular}{|c|c|c|c|c|c|c|c|c|c|}
\hline Variável & $\begin{array}{c}\text { Fator } \\
1\end{array}$ & $\begin{array}{c}\text { Fator } \\
2\end{array}$ & $\begin{array}{c}\text { Fator } \\
3\end{array}$ & $\begin{array}{c}\text { Fator } \\
4\end{array}$ & $\begin{array}{c}\text { Fator } \\
5\end{array}$ & $\begin{array}{c}\text { Fator } \\
6\end{array}$ & $\begin{array}{c}\text { Fator } \\
7\end{array}$ & $\begin{array}{c}\text { Fator } \\
8\end{array}$ & Comunalidade \\
\hline $\begin{array}{l}\text { Escolaridade do } \\
\text { produtor }\end{array}$ & 0,3179 & $\begin{array}{c}- \\
0,5728\end{array}$ & 0,2006 & 0,1084 & $\begin{array}{c}- \\
0,2688\end{array}$ & 0,2001 & 0,0105 & $\begin{array}{c}- \\
0,0656\end{array}$ & 0,4165 \\
\hline $\begin{array}{l}\text { Tempo que é } \\
\text { produtor de leite }\end{array}$ & 0,0098 & 0,7529 & 0,2394 & 0,0273 & $\begin{array}{c}- \\
0,1849\end{array}$ & 0,0884 & $\begin{array}{c}- \\
0,2225\end{array}$ & $-0,046$ & 0,2691 \\
\hline $\begin{array}{l}\text { Distância da } \\
\text { propriedade da sede } \\
\text { do município }\end{array}$ & 0,0209 & 0,1904 & $\stackrel{-}{0,5196}$ & 0,2205 & 0,0208 & 0,0408 & 0,0392 & 0,4967 & 0,3951 \\
\hline $\begin{array}{l}\text { Técnico visitou sua } \\
\text { propriedade para } \\
\text { orientá-lo sobre } \\
\text { gado de leite }\end{array}$ & 0,0724 & 0,3115 & 0,5864 & 0,0776 & $\begin{array}{c}- \\
0,1742\end{array}$ & 0,2246 & 0,2442 & 0,1622 & 0,3871 \\
\hline Sanidade & 0,0636 & $\begin{array}{c}- \\
0,0166\end{array}$ & 0,7779 & $\begin{array}{c}- \\
0,0023\end{array}$ & 0,1036 & $\begin{array}{c}- \\
0,0332 \\
\end{array}$ & $\begin{array}{c}- \\
0,1171\end{array}$ & 0,0903 & 0,3409 \\
\hline $\begin{array}{l}\text { Fez uso do crédito } \\
\text { rural no último ano }\end{array}$ & 0,1333 & $-0,037$ & $\begin{array}{c}- \\
0,2637\end{array}$ & 0,6410 & 0,0692 & 0,2098 & 0,1485 & $\begin{array}{c}- \\
0,1667\end{array}$ & 0,392 \\
\hline Tipo de aleitamento & 0,1259 & $\begin{array}{c}- \\
0,2058\end{array}$ & 0,0414 & 0,6829 & $\begin{array}{c}- \\
0,0855\end{array}$ & 0,1132 & $\begin{array}{c}- \\
0,0268\end{array}$ & 0,1848 & 0,4177 \\
\hline Resfriamento de leite & 0,1639 & 0,2318 & 0,2466 & 0,5713 & 0,0567 & $\begin{array}{c}- \\
0,2261\end{array}$ & 0,3113 & 0,0226 & 0,3801 \\
\hline $\begin{array}{l}\text { Número de filhos } \\
\text { trabalhando na } \\
\text { produção de leite }\end{array}$ & 0,0383 & 0,3173 & 0,1243 & 0,0482 & 0,5843 & $\begin{array}{c}- \\
0,0164\end{array}$ & $\begin{array}{c}- \\
0,2131\end{array}$ & 0,2459 & 0,4397 \\
\hline $\begin{array}{l}\text { Esposa executa } \\
\text { algum trabalho na } \\
\text { produção de leite }\end{array}$ & 0,2526 & 0,0832 & 0,0034 & 0,0123 & 0,7444 & 0,0613 & 0,104 & $\begin{array}{c}- \\
0,1597\end{array}$ & 0,3394 \\
\hline $\begin{array}{l}\text { Participação em } \\
\text { algum treinamento } \\
\text { (curso, palestra, dia } \\
\text { de campo) }\end{array}$ & 0,0828 & $\begin{array}{c}- \\
0,0244\end{array}$ & $-0,04$ & 0,0962 & 0,2053 & 0,6928 & 0,0765 & $\begin{array}{c}- \\
0,2511\end{array}$ & 0,3949 \\
\hline $\begin{array}{l}\text { Leite avaliado por } \\
\text { qualidade }\end{array}$ & 0,0286 & 0,0786 & 0,063 & 0,0605 & $\begin{array}{c}- \\
0,0826\end{array}$ & 0,7041 & $\begin{array}{c}- \\
0,1061\end{array}$ & 0,1931 & 0,4284 \\
\hline Tipo de sistema & 0,1651 & $\begin{array}{c}- \\
0,0708\end{array}$ & 0,1771 & $-0,108$ & $\begin{array}{c}- \\
0,0537\end{array}$ & 0,3288 & 0,5564 & 0,3662 & 0,3771 \\
\hline $\begin{array}{l}\text { O que precisa } \\
\text { melhorar }\end{array}$ & 0,0219 & 0,0343 & 0,0793 & $\begin{array}{c}- \\
0,1665\end{array}$ & 0,0303 & 0,0823 & $\overline{-}-\overline{8}$ & 0,0157 & 0,2945 \\
\hline Uso de concentrado & 0,0477 & 0,0154 & 0,1277 & $\begin{array}{c}- \\
0,0028\end{array}$ & $\begin{array}{c}- \\
0,0205\end{array}$ & $\begin{array}{c}- \\
0,0361\end{array}$ & 0,0789 & 0,7646 & 0,3813 \\
\hline
\end{tabular}

Fonte: Elaboração própria com base nos resultados da pesquisa

O Fator 1 explica 20,94\% da variação total da análise e se encontra fortemente correlacionado com variáveis da exploração leiteira e tecnologias da atividade. Esse fator apresentou correlações elevadas e positivas com as variáveis: produção de leite $\left(X_{1}\right)$, área total gado de leite $\left(X_{4}\right)$, vacas em lactação $\left(X_{5}\right)$, renda bruta que provém do leite $\left(X_{6}\right)$, mão de obra contratada $\left(X_{12}\right)$ e número ordenhas realizadas por dia $\left(X_{18}\right)$. Esse fator foi denominado como Escala e Fatores de Produção.

Com $11,38 \%$ da variância total, tem-se o Fator 2 . Esse representa o perfil do produtor e indica relação com o nível de conhecimento da atividade. Apresenta correlação positiva com as variáveis idade do produtor $\left(X_{7}\right)$ e tempo na atividade $\left(X_{9}\right)$ e correlação negativa com a variável escolaridade do produtor $\left(X_{8}\right)$. $\mathrm{A}$ denominação conferida a esse fator foi Experiência na Atividade. A correlação negativa da variável escolaridade demonstra que as propriedades, em que o produtor apresenta maior nível de escolaridade, possuem menores escores fatoriais para este fator.

Para Aleixo et al. (2007), quanto maior o nível de escolaridade dos produtores de leite, menor é a idade, o tempo na atividade e a dependência dessa atividade. Os autores enfatizam a importância de estratégias para formação dos produtores com menores níveis escolares, uma vez que, com maior nível de ensino, maiores serão as chances da incorporação de tecnologias, adoção de novos sistemas de produção e aumento da produtividade. Entretanto, quando se analisa pelo ponto de vista da idade, quanto maior a magnitude dessa variável e o tempo disposto na atividade, maiores são os níveis de conhecimento do processo produtivo (experiência), o que contribui para implementação de novas tecnologias.

O terceiro fator explica $7,73 \%$ da variância e está positivamente relacionado com as variáveis: técnico visitou sua propriedade para orientá-lo sobre gado de leite $\left(X_{14}\right)$ e sanidade $\left(X_{1}\right)$. No entanto, é vista uma correlação negativa entre as variáveis supracitadas e a distância da propriedade a sede do município ( $\left.X_{2}\right)$. Esse fator foi definido como Assistência Técnica ao Produtor. 
Com relação ao terceiro fator, Castro et al. (1998) explicam que a sanidade e a assistência técnica tendem a ter relação inversa com a distância da propriedade da sede do município, pois, para obter boa qualidade do leite, faz-se necessário ter o máximo de cuidado com a sanidade do rebanho, receber assistência técnica e receber o transporte do produto. No entanto, muitas vezes, essas ações acabam sendo prejudicadas pela distância da propriedade em relação ao meio urbano. Assim, quanto maior a distância, menores serão as chances do produtor de leite receber mais visitas técnicas, de obter as vacinas necessárias para cuidar do rebanho e de haver o recolhimento do leite mais de duas vezes na semana.

Já o Fator 4, com $6,83 \%$ da variância total, está correlacionado positivamente com as variáveis: fez uso do crédito rural no último ano $\left(X_{15}\right)$, tipo de aleitamento $\left(X_{19}\right)$ e resfriamento de leite $\left(X_{20}\right)$. Analisando o grupo de variáveis correlacionadas, esse fator recebe a denominação de Apoio Financeiro e Aspectos Técnicos.

O Fator 5 explica $5,55 \%$ da variância e está positivamente relacionado com as variáveis: filhos trabalhando na produção de leite $\left(X_{10}\right)$ e esposa executa algum trabalho na produção de leite $\left(X_{11}\right)$, sendo denominado de Mão de Obra Familiar. Chama atenção que a mão de obra predominante, nas propriedades analisadas, é familiar, mostrando que, quanto maior a participação da família no processo produtivo, maiores os escores fatoriais.

Com 5,38\% da variância, tem-se o Fator 6 , que está correlacionado positivamente com as variáveis: participação em algum treinamento (curso, palestra, dia de campo) $\left(X_{13}\right)$ e leite avaliado por qualidade $\left(X_{21}\right)$; tal fator é denominado Capacitação do Produtor.

O Fator 7 apresenta $5 \%$ de variância total e está relacionado positivamente com a o tipo de sistema $\left(X_{3}\right)$ e negativamente com o que precisa melhorar $\left(X_{22}\right)$. A denominação conferida a esse fator foi Característica da Estrutura Produtiva. A variável "o que precisa melhorar", como já demonstrado, é dividida entre orientação técnica, treinamento de capacitação dos empregados, tanque de resfriamento, melhoria das estradas até a propriedade e acesso ao crédito rural. Assim, dentre todas essas opções, os produtores argumentaram sentirem mais falta da assistência técnica. De acordo com Vilela et al. (2016), a assistência técnica está diretamente relacionada com a estrutura produtiva, por meio da sanidade, treinamentos, apresentação de novas tecnologias, melhorias no rebanho, entre outras coisas. Quanto mais os produtores apresentarem a falta de assistência técnica, mais atrasado será o seu sistema produtivo.

Por fim, tem-se o Fator 8 que explica 4,69\% da variância total e está relacionado, de forma positiva, com a variável uso de concentrado $\left(X_{16}\right)$. Atribui-se a esse fator a denominação de Nutrição. Manteve-se esse fator na análise devido à importância da variável uso de concentrado, pois ela reflete o manejo e a alimentação introduzida na produção, ou seja, boas práticas que conduzem a níveis mais elevados de produtividade.

Com uso das cargas fatoriais, são adquiridos os escores fatoriais para cada observação com relação a cada fator. Esses escores são utilizados na análise de clusters para agrupar produtores de leite conforme suas similaridades. O método de agrupamento identificou três grupos (tipos) de produtores de leite: Grupo A com 33 produtores de leite (17,01\%), Grupo B com 89 (45,88\%) e Grupo C com 72 (37,11\%).

Para identificar o padrão tecnológico nos diferentes tipos de produtores, foram usadas variáveis que se destacam na literatura sobre tipificação e tecnologia - estudos de Wagner (2003), Chinelatto Neto et al. (2005), Aleixo et al. (2007), Werncke et al. (2016), Vilela et al. (2016) - tais como: genética dos animais; equipamentos e infraestrutura (instalações); capacitação da mão de obra; nutrição; área destinada a produção de leite; número de vacas; produção e/ou produtividade, dentre outras. No Quadro 2, têm-se as variáveis utilizadas para identificar o padrão tecnológico dos grupos de produtores de leite.

Quadro 2 - Características tecnológicas dos grupos de produtores de leite

\begin{tabular}{|c|c|c|c|}
\hline Variáveis & Grupo A (33) & Grupo B (89) & Grupo C (72) \\
\hline Produtividade & 17,68 litros/vaca/dia & 14,22 litros/vaca/dia & 15,08 litros/vaca/dia \\
\hline Produção de leite & $\begin{array}{l}\text { Produção média } \\
773,09 \text { litros/dia }\end{array}$ & $\begin{array}{l}\text { Produção média } \\
167,64 \text { litros/dia }\end{array}$ & $\begin{array}{l}\text { Produção média } \\
247,61 \text { litros/dia }\end{array}$ \\
\hline Número de vacas em lactação & Média de 40 vacas & $\begin{array}{l}\text { Média de } 13 \\
\text { vacas }\end{array}$ & Média de 18 vacas \\
\hline $\begin{array}{l}\text { Área total destinada ao gado de } \\
\text { leite }\end{array}$ & Média de 25 ha. & Média de 12 ha. & Média de 11 ha. \\
\hline $\begin{array}{l}\text { Número de filhos trabalhando na } \\
\text { produção de leite }\end{array}$ & $\begin{array}{l}0 \text { filhos }=26 \\
2 \text { filhos }=5 \\
2 \text { filhos }=2 \\
3 \text { filhos }=0\end{array}$ & $\begin{array}{l}0 \text { filhos }=44 \\
1 \text { filho }=34 \\
2 \text { filhos }=8 \\
3 \text { filhos }=3\end{array}$ & $\begin{array}{l}0 \text { filhos }=42 \\
1 \text { filho }=27 \\
2 \text { filhos }=1 \\
3 \text { filhos }=2\end{array}$ \\
\hline $\begin{array}{l}\text { Esposa executa algum trabalho na } \\
\text { produção de leite }\end{array}$ & $\begin{array}{l}69 \% \text { executa } \\
\text { trabalho }\end{array}$ & $\begin{array}{l}94 \% \text { executa algum } \\
\text { trabalho }\end{array}$ & $\begin{array}{l}96 \% \text { executa algum } \\
\text { trabalho }\end{array}$ \\
\hline
\end{tabular}




\begin{tabular}{|c|c|c|c|}
\hline Variáveis & Grupo A (33) & Grupo B (89) & Grupo C (72) \\
\hline Raça & $\begin{array}{l}36 \% \text { das } \\
\text { propriedades } \\
\text { apresentam vacas } \\
\text { da raça ouro } \\
\text { holandês }\end{array}$ & $\begin{array}{l}43 \% \text { das } \\
\text { propriedades } \\
\text { apresentam vacas } \\
\text { da raça ouro } \\
\text { holandês }\end{array}$ & $\begin{array}{l}35 \% \text { das } \\
\text { propriedades } \\
\text { apresentam vacas } \\
\text { da raça ouro } \\
\text { holandês }\end{array}$ \\
\hline $\begin{array}{l}\text { Participação em algum } \\
\text { treinamento } \\
\text { (curso, palestra, dia de campo) }\end{array}$ & $\begin{array}{l}73 \% \text { não } \\
\text { participaram de } \\
\text { treinamento }\end{array}$ & $\begin{array}{l}52 \% \text { não } \\
\text { participaram de } \\
\text { treinamento }\end{array}$ & $\begin{array}{l}49 \% \text { não } \\
\text { participaram de } \\
\text { treinamento }\end{array}$ \\
\hline Uso de concentrado & $\begin{array}{l}91 \% \text { usaram } \\
\text { concentrado }\end{array}$ & $\begin{array}{l}66 \% \text { usaram } \\
\text { concentrado }\end{array}$ & $\begin{array}{l}99 \% \text { usaram } \\
\text { concentrado }\end{array}$ \\
\hline Resfriamento de leite & $\begin{array}{l}79 \% \text { fazem } \\
\text { resfriamento do leite } \\
\text { em tanque de } \\
\text { expansão individual }\end{array}$ & $\begin{array}{l}75 \% \text { fazem } \\
\text { resfriamento do leite } \\
\text { em tanque de } \\
\text { expansão individual }\end{array}$ & $\begin{array}{l}97 \% \text { fazem } \\
\text { resfriamento do leite } \\
\text { em tanque de } \\
\text { expansão individual }\end{array}$ \\
\hline Tipo de aleitamento & $\begin{array}{l}70 \% \text { usaram } \\
\text { aleitamento artificial }\end{array}$ & $\begin{array}{l}56 \% \text { usaram } \\
\text { aleitamento artificial }\end{array}$ & $\begin{array}{l}82 \% \text { usaram } \\
\text { aleitamento artificial }\end{array}$ \\
\hline $\begin{array}{l}\text { Fez uso do crédito rural no último } \\
\text { ano }\end{array}$ & $\begin{array}{l}55 \% \text { usaram crédito } \\
\text { rural }\end{array}$ & $\begin{array}{l}54 \% \text { usaram crédito } \\
\text { rural }\end{array}$ & $\begin{array}{l}72 \% \text { usaram crédito } \\
\text { rural }\end{array}$ \\
\hline $\begin{array}{l}\text { Técnico visitou sua propriedade } \\
\text { para orientá-lo sobre gado de leite }\end{array}$ & $\begin{array}{l}91 \% \text { receberam } \\
\text { visita do técnico }\end{array}$ & $\begin{array}{l}67 \% \text { receberam } \\
\text { visita do técnico }\end{array}$ & $\begin{array}{l}81 \% \text { receberam } \\
\text { visita do técnico }\end{array}$ \\
\hline $\begin{array}{l}\text { Mão de obra contratada para } \\
\text { manejo do gado de leite }\end{array}$ & $\begin{array}{l}60,6 \% \text { não } \\
\text { apresentam mão de } \\
\text { obra contratada }\end{array}$ & $\begin{array}{l}96,6 \% \text { não } \\
\text { apresentam mão de } \\
\text { obra contratada }\end{array}$ & $\begin{array}{l}97,2 \% \text { não } \\
\text { apresentam mão de } \\
\text { obra contratada }\end{array}$ \\
\hline
\end{tabular}

Fonte: Elaboração própria com base nos resultados da pesquisa

Os produtores que compõem o Grupo A apresentam, em média, maior volume de produção, número de vacas em lactação, área destinada ao gado de leite e produtividade, e menor número de filhos trabalhando na produção de leite. São produtores que receberam mais assistência técnica e usaram mais mão de obra contratada que os demais grupos. Esses produtores são considerados com padrão tecnológico avançado.

Entretanto, os produtores do Grupo C, mesmo não demonstrando uma média de produção e produtividade elevada, destacam-se pela maior participação em treinamentos, pela esposa envolver-se ativamente na atividade leiteira (exerce atividades como: ordenhar, registrar despesas e receitas, administrar a propriedade, entre outras) e pela mão de obra envolvida na atividade, cuja maioria é familiar. Por fim, os produtores desse grupo usam mais concentrados para vacas em lactação, aleitamento artificial e são os que mais utilizam tanque de expansão individual para resfriamento do leite e o crédito rural. Os produtores desse grupo apresentam nível tecnológico intermediário.

O Grupo B caracteriza-se por menor nível de produção e, também, baixa produtividade de leite, pouca área destinada à produção de leite, grande parte da mão de obra utilizada no processo produtivo é familiar, sendo que a esposa participa de algumas atividades. Embora o número de vacas em lactação seja baixo, visà-vis aos demais grupos, grande parte dos produtores de leite apresentam vacas da raça holandesa. Assim, os produtores desse grupo (conhecidos como tradicionais) possuem baixo padrão tecnológico.

O baixo padrão tecnológico é dominante dentre os produtores de leite (Grupo B - 89 produtores), com características aquém quando comparados aos demais produtores dos outros dois grupos. Eles fazem menor uso de crédito rural e possuem menor acessibilidade à educação (cursos, palestras, treinamentos, etc.) e assistência técnica. Mas o padrão tecnológico intermediário encontra-se muito forte nessa região (Grupo C 72 produtores), os produtores com tal padrão, conforme Montoya et al. (2014), apresentam a cultura leiteira como a principal fonte de renda da propriedade, fazem uso do crédito rural para melhorar a estrutura da propriedade e recebem constantemente assistência técnica.

O padrão tecnológico avançado é menos presente na região Corede Produção/RS (Grupo A - 33 produtores), mas apresenta maiores níveis de produtividade. Essa região pratica o sistema semiconfinado e, sempre, está investindo na atividade leiteira. Esses três padrões tecnológicos vão ao encontro dos retratados na literatura, entre eles, os apresentados por Wagner et al. (2004) e Todde et al. (2016), que caracterizam os produtores de leite de sua pesquisa como tradicional e baixa mecanização, em transição e mecanizados, moderno convencional e alta mecanização, respectivamente.

Com uso da análise discriminante, foi testada a classificação realizada pela análise de cluster e identificadas quais variáveis (fatores tecnológicos) têm maior poder para discriminar os padrões tecnológicos dentre grupos de produtores de leite. As variáveis utilizadas foram: número de filhos trabalhando na produção 
de leite; esposa executa algum trabalho na produção de leite; área total destinada ao gado de leite; participação em algum treinamento (curso, palestra, dia de campo); produtividade; uso de concentrado; resfriamento de leite; tipo de aleitamento; fez uso do crédito rural no último ano; técnico visitou sua propriedade para orientá-lo sobre gado de leite; mão de obra contratada e raça.

O teste de normalidade das variáveis explicativas apontou violação do pressuposto de igualdade, pois não há igualdade das matrizes de variância/covariância dos grupos de produtores (teste M-Box significativo a $1 \%$ de probabilidade). Nesse caso, Reis (1997) e Mingoti (2005) indicam o uso da função quadrática para realizar a classificação ótima dos grupos de produtores obtidos da análise de cluster.

$\mathrm{Na}$ Tabela 4, têm-se os resultados da classificação utilizando a função discriminante quadrática. No geral, a porcentagem de acerto global foi igual a $80,42 \%$, indicando uma boa qualidade de classificação dos grupos de produtores, em específico os grupos $\mathrm{A}$ e $\mathrm{C}$, que apresentaram maior proporção de acerto da classificação: 93,94\% para o Grupo A e 88,9\% para o Grupo C. A menor classificação de acerto ficou com o Grupo B $(58,43 \%)$, indicando que alguns produtores de leite, de acordo com as variáveis utilizadas para discriminar, foram classificados incorretamente ${ }^{3}$.

Tabela 4 - Resultados da classificação utilizando a função discriminante quadrática

\begin{tabular}{lrrrr}
\hline & \multicolumn{4}{c}{ Classificação - Função Discriminante } \\
\cline { 2 - 4 } & Grupo A & Grupo B & Grupo C & Total \\
\hline Grupo A & $93,94 \%$ & $0,00 \%$ & $46,06 \%$ & $100 \%$ \\
\hline Grupo B & $8,99 \%$ & $58,43 \%$ & $32,58 \%$ & $100 \%$ \\
\hline Grupo C & $6,94 \%$ & $4,17 \%$ & $88,89 \%$ & $100 \%$ \\
\hline Percentual geral de acertos & \multicolumn{4}{c}{} \\
\hline
\end{tabular}

Fonte: Elaboração própria com base nos resultados da pesquisa

Para complementar o estudo, foram identificadas quais variáveis (fatores tecnológicos) têm maior poder para discriminar os padrões tecnológicos dentre os grupos de produtores de leite por meio da função discriminante. O teste Lambda Wilks ou teste da razão de verossimilhança, em nível de significância de 1\%, rejeitou a hipótese nula $\left(\mathrm{H}_{0}\right)$, confirmando que as duas funções estimadas são capazes de discriminar os grupos. Além disso, quanto maior o autovalor, maior é a capacidade de a função discriminante separar os grupos.

As funções foram estimadas pelo método de simultâneo, em que nenhuma variável é descartada e não se considera o sinal dos coeficientes, pois o objetivo foi identificar quais variáveis apresentam maior contribuição relativa para diferenciar os grupos de produtores. Ressalta-se que, quanto maior o coeficiente das variáveis independentes, maior será o poder discriminatório dela sobre a função.

$\mathrm{Na}$ Tabela 5, encontram-se os resultados da Função 1 e da Função 2. A Função 1 denota maior capacidade para separar o Grupo A dos demais grupos. Em ordem decrescente, estão dispostas as variáveis que apresentam maior poder para discriminar os padrões tecnológicos do Grupo A em relação aos demais. Portanto, as principais variáveis são: o número de filhos trabalhando; o trabalho da esposa na produção de leite; e área total destinada ao gado de leite.

Com menor capacidade para separar os grupos, tem-se a Função 2. As variáveis, dessa função, com maiores coeficientes apresentam maior poder para discriminar os padrões tecnológicos dos produtores do Grupo B em relação aos do C. Em ordem decrescente, as variáveis uso de concentrado, resfriamento de leite e tipo de aleitamento se destacam.

Tabela 5 - Variáveis discriminantes e coeficientes

\begin{tabular}{|c|c|c|}
\hline Variáveis & Função 1 & Função 2 \\
\hline Número de filhos trabalhando na produção de leite & $-0,752$ & 0.077 \\
\hline Esposa executa algum trabalho na produção de leite & 0,450 & -0.052 \\
\hline Área total destinada ao gado de leite & 0,332 & 0.014 \\
\hline $\begin{array}{l}\text { Participação em algum treinamento } \\
\text { (curso, palestra, dia de campo) }\end{array}$ & $-0,147$ & -0.021 \\
\hline Produtividade & 0,131 & -0.104 \\
\hline Uso de concentrado & 0.063 & $-0,665$ \\
\hline Resfriamento de leite & -0.076 & $-0,429$ \\
\hline Tipo de aleitamento & -0.004 & $-0,403$ \\
\hline Fez uso do crédito rural no último ano & -0.062 & $-0,260$ \\
\hline $\begin{array}{l}\text { Técnico visitou sua propriedade } \\
\text { para orientá-lo sobre gado de leite }\end{array}$ & 0.124 & $-0,242$ \\
\hline Mão de obra contratada & -0.132 & 0,197 \\
\hline Raça & -0.012 & 0,118 \\
\hline
\end{tabular}

Fonte: Elaboração própria com base nos resultados da pesquisa

\footnotetext{
${ }^{3}$ Conforme a autora Mingoti (2005), uma proporção de acerto baixa pode resultar em uma classificação errônea dos indivíduos no grupo, indicando a alteração de variáveis, entretanto foram preservadas as variáveis utilizadas na análise discriminante, pois foram escolhidas conforme a literatura e a disponibilidade no questionário "Diagnóstico da Produção de Leite - Corede Produção".
} 
As variáveis número de filhos trabalhando na produção de leite e se esposa executa algum trabalho na produção de leite representam a mão de obra utilizada na pecuária leiteira, tais apresentam maior poder para diferenciar o padrão tecnológico avançado (Grupo A) dos demais grupos. Segundo Aleixo et al. (2007), Cervo et al. (2018) e Resende et al. (2016), os produtores com maior adoção de tecnologia são propícios a demandar menos mão de obra, ou seja, a automação e a robótica tendem a substituir o trabalho manual e, caso haja a permanência da mão de obra na atividade, ela precisa ser especializada.

Uso de concentrado, resfriamento de leite e tipo de aleitamento são as variáveis com maior poder para diferenciar o padrão tecnológico dos produtores do Grupo B (baixo) em relação ao Grupo C (intermediário). A nutrição do rebanho é importante no desempenho produtivo e na qualidade final do produto. O resfriamento de leite, em tanque de expansão individual, é necessário para manter a qualidade da matéria-prima, e o aleitamento artificial reduz a quantidade de leite destinada ao bezerro, permite a desmama precoce e regula os horários em que o bezerro irá se alimentar (Lange et al. 2016; Werncke et al., 2016; Cervo et al., 2018).

As demais variáveis não possuem grande poder para diferenciar os padrões tecnológicos dos grupos de produtores de leite, entretanto a variável produtividade chama atenção pelo seu baixo poder de discriminação. Chinelatto Neto et al. (2005) e Aleixo et al. (2007) constataram, em suas pesquisas, que a produtividade não foi importante na discriminação, pois ela manteve-se constante entre os grupos. Aleixo et al. (2007) explicam que, muitas vezes, o aumento na produção não é acompanhado pelo incremento tecnológico, tornando essa variável insignificante na diferenciação de grupos. Vieira Filho e Silveira (2012) relatam que o comportamento da produtividade e dos custos não estão apenas relacionados com adoção de uma inovação, dependem da capacidade de aprendizagem e de absorção do conhecimento de cada produtor.

\section{CONCLUSÃO}

Este estudo se propôs a identificar o padrão tecnológico dentre os diferentes tipos de produtores de leite presentes na região Corede Produção/RS. Para tanto, aplicou-se a análise fatorial exploratória para resumir o número de variáveis, clusters para agrupar os produtores de leite e identificar seus respectivos padrões tecnológicos e discriminante múltipla para identificar quais fatores tecnológicos apresentam maior poder para discriminar os padrões tecnológicos dentre grupos de produtores de leite.

A partir da análise fatorial exploratória, foi possível identificar oito fatores que foram nomeados e utilizados na análise de clusters. Por meio dessas análises, identificaram-se três padrões tecnológicos dentre os produtores de leite que a região em estudo contempla, caracterizados em: grupo $A$, avançados, grupo B, tradicionais (baixo padrão) e grupo $\mathrm{C}$, intermediários. Os produtores pertencentes ao tipo avançado e intermediário se destacam na adoção de tecnologia para aumentar a produção, entretanto os produtores do tipo tradicional (com presença elevada na região) mostram menor adoção de tecnologia. Esse pluralismo tecnológico constatado dentre os produtores de leite da Mesorregião Noroeste Rio-grandense, uma das principais bacias leiteira do Brasil, também é encontrado por outros estudiosos da área em diferentes regiões brasileiras e internacionais. Tais fatos reforçam as dificuldades na inserção dos recursos tecnológicos disponíveis na cadeia leiteira para os produtores e a falta de difusão de conhecimento por parte da assistência técnica e acesso à educação (cursos, palestras, treinamentos etc.).

A análise, também, tem o teor de auxiliar no desenho de políticas públicas e na definição de prioridades para o setor, como, por exemplo, uma política que ofereça financiamento para aquisição de máquinas e equipamentos de acordo suas características tecnológicas (tipo de produtor) de modo a aumentar a produção ou auxiliar na redução das disparidades tecnológicas entre os produtores de leite. Uma vez que, além de apresentar os padrões tecnológicos presentes na região, também fornece as variáveis que têm maior poder para identificar o padrão tecnológico do produtor de leite solicitante de uma política, tais como: número de filhos trabalhando na produção de leite; esposa executa algum trabalho na produção de leite; área total destinada ao gado de leite; uso de concentrado; resfriamento de leite; tipo de aleitamento; e, uso do crédito rural no último ano.

\section{AGRADECIMENTO}

O presente trabalho foi realizado com apoio da Coordenação de Aperfeiçoamento de Pessoal de Nível Superior - Brasil (CAPES) - Código de Financiamento 001

\section{REFERÊNCIAS}

ALEIXO, S. S.; SOUZA, J. G.; FERRAUDO, A. S. Técnicas de análise multivariada na determinação de grupos homogêneos de produtores de leite. Revista Brasileira de Zootecnia, Viçosa, v. 36, n. 6, p. 2168-2175, 2007. Disponível em: http://www.scielo.br/pdf/rbz/v36n6s0/29.pdf. Acesso em: 23 mar. 2018.

CASTRO, Á. et al. Typologies of Dairy Farms with Automatic Milking System in Northwest Spain and Farmers' 
Satisfaction. Italian Journal of Animal Science, London, v. 14, n. 3559, p. 207-219, fev. 2016. Disponível em: https://www.tandfonline.com/doi/full/10.4081/ijas.2015.3559. Acesso em: 21 mar. 2018.

CASTRO, C. C. de et al. Estudo da Cadeia Láctea do Rio Grande do Sul: uma Abordagem das Relações entre os Elos da Produção, Industrialização e Distribuição. RAC, [s.I.], v. 2, n. 1, p. 143-164, jan. 1998. Disponível em: http://www.scielo.br/pdf/rac/v2n1/v2n1a09.pdf. Acesso em: 10 out. 2018.

CERVO, Heitor José et al. Spatial distribution of productive, environmental, and socioeconomic factors to discriminate dairy cattle production in the South of Brazil. Ciência Animal Brasileira. 2018, v. 19. Disponível em: https://doi.org/10.1590/1809-6891v19e-33194. Acesso em: 22 maio 2021.

CHINELATTO NETO, A.; CASTRO, G. P. C.; LIMA, J. E. Uso de análise estatística multivariada para tipificação de produtores de leite de Minas Gerais. Organizações Rurais \& Agroindustriais, Lavras, v. 7, n. 1, p. 114-121, 2005. Disponível em: http://www.redalyc.org/articulo.oa?id=87817147010. Acesso em: 05 fev. 2018.

CORRAR, L. J.; PAULO, E.; DIAS FILHO, J. M. Análise multivariada: para os cursos de administração, ciências contábeis e econômicas. São Paulo: Atlas, 2009. 541 p.

FUNDAÇÃO DE ECONOMIA E ESTATÍSTICA. Perfil Socioeconômico. Disponível em: https://www.fee.rs.gov.br/. Acesso em: 10 abr. 2018.

GARCIA FILHO, D. P. Análise e diagnóstico de sistemas agrários - guia metodológico. Brasília: INCRA/FAO, 1999.

GUAMÁN, R. A. G.; MOPOSITA, D. M.; RODRÍGUEZ, L. M. C. Caracterización de Sistemas Productivos Lecheros en Condiciones de Montaña, Parroquia Químiag, Provincia Chimborazo, Ecuador. Rev. Prod. Anim, Cuba, v. 2, n. 29, p.14-24, maio 2017. Disponível em: http://scielo.sld.cu/scielo.php?script=sci arttext\&pid=S2224-79202017000200003. Acesso em: 20 out. 2018.

HAIR, J. F. et al. Análise multivariada de dados. 6. ed. Porto Alegre: Bookman, 2009. 688 p.

INSTITUTO BRASILEIRO DE GEOGRAFIA E ESTATÍSTICA. Censo Agropecuário 2017: resultados preliminares. Disponível em: https://sidra.ibge.gov.br/pesquisa/censo-agropecuario/censo-agropecuario-2017. Acesso em: 06 out. 2018a.

INSTITUto BRASIleiRo de GeOGRAFIA E EStATístiCA. Pesquisa Pecuária Municipal: Produção de origem animal. Disponível em: https://sidra.ibge.gov.br/Tabela/74. Acesso em: 05 mar. 2018b

JANK, M. S.; GALAN, V B. Competitividade do sistema agroindustrial do leite. In: Competitividade no agribusiness brasileiro [S.I.: S.n.], 1998.

KAOUCHE-ADJLANE, S.; GHOZLANE, F.; MATI, A. Tipologia dos sistemas de agricultura leiteira na Bacia do Mediterrâneo (caso da Argélia). Biotechnology In Animal Husbandry, Belgrade-Zemun, v. 31, n. 3, p. 385-396, 2015. DOI:10.2298/BAH1503385K. Acesso em: 22 mar. 2018.

KOSTROWICKI, J. Agricultural Typology Concept and Method. Agricultural Systems, [S.I], v. 2, n. 1, p. 33-45, jan. 1977. Disponível em: https://www.sciencedirect.com/science/article/pii/0308521X77900154. Acesso em: 15 fev. 2018.

LANGE, M. J. et al. Typology of dairy production systems based on the characteristics of management in the Region of West Paraná. Semina: Ciências Agrárias, Londrina, v. 37, n. 1, p. 473-482, fev. 2016. Disponível em: http://dx.doi.org/10.5433/1679-0359.2016v37n1p473. Acesso em: 24 mar. 2018

MINISTÉRIO DA AGRICULTURA, PECUÁRIA E ABASTECIMENTO. Produção de Leite. Disponível em: http://www.agricultura.gov.br/. Acesso em: 10 abr. 2018.

MAS-COLLEL, A.; WHINSTON, M. D.; GREEN, J.R. Microeconomic theory. New Yourk: Oxford University Press, 1995 MINGOTI, S. A. Análise de dados através de métodos de estatísticas multivariadas: uma abordagem aplicada. Belo Horizonte: UFMG, 2005. 297p.

MONTOYA, M. A.; PASQUAL, C. A.; FINAMORE, E. B. Panorama da produção leiteira no Rio Grande do Sul: perspectiva e gestão nas propriedades no Corede Produção. Passo Fundo: Editora UPF, 2014. 141 p.

PEROBELLI, F. S.; ARAÚJO, I. F.; CASTRO, L. S. As dimensões espaciais da cadeia produtiva do leite em Minas Gerais. Nova Economia. 2018, v. 28, n. 01 , pp. 297-337. Disponível em: https://doi.org/10.1590/0103-6351/4789. Acesso em: 24 maio 2021.

REIS, E. Estatística Multivariada Aplicada. Lisboa: Síbalo, 1997.

RESENDE, J.C.; PEREIRA, R.A.N.; PEREIRA, M.N. Indicadores de desempenho de fazendas leiteiras de Minas Gerais. Arq. Bras. Med. Vet. Zootec., Belo Horizonte, v. 68, n. 4, p. 1033-1042, 2016. Disponível em: http://dx.doi.org/10.1590/1678-4162-8218. Acesso em: 15 ago. 2018.

SOUZA, S. S. P. V. Diagnóstico de unidades produtoras de leite no Planalto Norte Catarinense: diagnóstico de unidades produtoras de leite no Planalto Norte Catarinense. 2015. 115 f. Dissertação (Mestrado em Agroecossistemas) - UFSC, Florianópolis, 2015. Disponível em: https://repositorio.ufsc.br/handle/123456789/158801. Acesso em: 05 maio 2018.

TODDE, G. et al. A multivariate statistical analysis approach to characterize mechanization, structural and energy profile in Italian dairy farms. Energy Reports, [s.I.], v. 2, p.129-134, nov. 2016. Disponível em: https://www.sciencedirect.com/science/article/pii/S2352484716300191. Acesso em: 03 nov. 2018.

VIEIRA FILHO, J. E. R.; SILVEIRA, J. M. F. J. Mudança tecnológica na agricultura: uma revisão crítica da literatura e o papel das economias de aprendizado. Revista de Economia e Sociologia Rural, v. 50, n. 4, p. 721-742, 2012. 
Disponível em: https://doi.org/10.1590/S0103-20032012000400008. Acesso em: 20 maio. 2021.

VILELA, D. et al. A evolução do leite no Brasil em cinco décadas. Revista de Política Agrícola, Brasília, v. 26, n. 1, p. 5-24, jan. 2017. Disponível em: https://seer.sede.embrapa.br/index.php/RPA/article/view/1243. Acesso em: 05 jul. 2018.

VILELA, D. et al. Pecuária de leite no Brasil: cenários e avanços tecnológicos. Brasília: Embrapa, 2016. 435 p.

WAGNER, S. A. O leite observado através de diferentes tipologias nas unidades de produção familiar no Rio Grande do Sul/BR e suas relações com formas organizativas e inovações tecnológicas. 2003. $134 \mathrm{f}$. Tese (Doutorado em Ciências Veterinária) - UFRGS, Porto Alegre, 2003. Disponível em: http://www.ufrgs.br/cursopgdr/downloadsSerie/derad017.pdf. Acesso em: 22 mar. 2018.

WAGNER, S. A.; GEHLEN, I.; WIEST, J. M. Padrão tecnológico em unidades de produção familiar de leite no Rio Grande do Sul relacionado com diferentes tipologias. Ciência Rural, Santa Maria, v. 34, n. 5, p. 1579-1584, set. 2004. Disponível em: http://www.scielo.br/pdf/cr/v34n5/a39v34n5.pdf. Acesso em: 08 abr. 2018.

WERNCKE, D. et al. Qualidade do leite e perfil das propriedades leiteiras no sul de Santa Catarina: abordagem multivariada. Arquivo Brasileiro de Medicina Veterinária e Zootecnia, [S.I.], v. 68, n. 2, p. 506-516, abr. 2016. Disponível em: http://www.scielo.br/pdf/abmvz/v68n2/0102-0935-abmvz-68-02-00506.pdf. Acesso em: 16 mar. 2018.

ZOCCAL, R. et al. A inserção do Brasil no mercado internacional de lácteos. Juiz de Fora: Embrapa Gado de Leite, 2005. $180 \mathrm{p}$. 
